\title{
Melatonin reduced endometrial hyperplasia induced by estradiol in female albino rats
}

\author{
Heba A. Abdel-Hamid ${ }^{1}$, Nagwa M. Zenhom² and Nisreen D. M. Toni ${ }^{3}$ \\ ${ }^{1}$ Medical Physiology Department, Faculty of Medicine, Minia University, Minia, Egypt \\ ${ }^{2}$ Biochemistry Department, Faculty of Medicine, Minia University, Minia, Egypt \\ ${ }^{3}$ Pathology Department, Faculty of Medicine, Minia University, Minia, Egypt
}

\begin{abstract}
Melatonin, the pineal gland hormone, plays a crucial role in regulation of neuroendocrine and defensive functions, free radicals neutralization, and suppresses angiogenesis, proliferation and cancer. The purpose of designing our study is to assess the effect of estradiol benzoate and its combination with melatonin on uteri of female albino rats. For 4 weeks, the present study was conducted on thirty six female rats separated into 3 groups: Control group (rats received the vehicle), EB group (rats were treated by estradiol benzoate $(600 \mu \mathrm{g} / \mathrm{kg}$ intramuscular) for induction of endometrial hyperplasia), and $\mathrm{EB}+\mathrm{Mel}$ group (rats were treated with estradiol benzoate $(600 \mu \mathrm{g} / \mathrm{kg}$ ) plus melatonin $(50 \mu \mathrm{g} / \mathrm{ml})$ added to drinking water. Melatonin administration reduced estradiol benzoate-induced endometrial hyperplasia and prevented the occurrence of atypia associated with a significant reduction in lipid peroxide level and NF- $\kappa B$ mRNA and a significant rise in immune-expression of caspase-3, interleukin-2 (IL-2) mRNA and total antioxidant levels in uterine tissues. The results demonstrated that melatonin reduced estradiol benzoate action on the endometrium.
\end{abstract}

Key words: Melatonin - Estradiol benzoate - Endometrial hyperplasia - Caspase-3 - NF- $\mathrm{B}$

\section{Introduction}

Endometrial hyperplasia is an abnormal thickening of endometrium due to excess estrogen exposure or low progesterone which counteracts the enhancing action of estrogen on growth. Due to the associated hormonal changes, it is most common in females who are postmenopausal or have reached the reproductive age (Clement et al. 2017). It may also happen secondary to diabetes, overweight, hypertension, or polycystic ovary. It is manifested by abnormal vaginal bleeding such as menorrhagia, postmenopausal bleeding and inter-menstrual bleeding (Kaushal et al. 2017). Simple and complex endometrial hyperplasia are two variable types of hyperplasia. In simple type, there is an equal thickening of both gland cells and stroma with rounded gland shape. In complex type, there is increased gland cell proliferation with lesser stromal involvement accompanied by overcrowding of glands which are variable in the shape and size. Atypia

Correspondence to: Heba Ali Abdel-Hamid, Medical Physiology Department, Faculty of Medicine, Minia University, Minia, Egypt E-mail: heba_physiology@yahoo.com may be present or absent in both types which points to abnormally high nuclear size with dense chromatin and may lead to endometrial cancer (Sobczuk and Sobczuk 2017).

Melatonin is mostly synthesized from tryptophan amino acid which is hydroxylated by the tryptophan-5-hydroxylase to form 5-hydroxytryptophan, then decarboxylated by the 5-hydroxytryptophan decarboxylase to form serotonin. Two enzymes converting serotonin to melatonin are found mainly in the pineal gland. Serotonin is first acetylated by arylalkylamine- $\mathrm{N}$-acetyltransferase to give $\mathrm{N}$-acetylserotonin and then methylated to give melatonin by acetylserotoninO-methyltransferase (Tordjman et al. 2017). In a circadian manner, melatonin is released nightly with high level and regulates a variety of important central and peripheral actions related to circadian rhythms. It regulates the functions of different systems including the brain, immune, gastrointestinal, cardiovascular, kidney, skeletal and endocrine systems (González-González et al. 2018).

Melatonin also regulates the functions of female genital system where melatonin receptors were detected specially in the ovary and uterus. It controls the growth of cells in female genital system via modification of estrogen and progesterone 
receptors expression (Li et al. 2017). Chuffa et al. (2013) reported that treatment of rats with melatonin decreased estradiol and increased progesterone and was associated with down-regulation of oviduct estrogen receptor alpha (ER- $\alpha)$, estrogen receptor beta (ER- $\beta$ ) and uterine ER- $\beta$ and upregulation of ovarian progesterone receptors and melatonin receptors (ovarian and uterine). Previous studies suggested that the anticancer effect of melatonin may be due to its antagonistic action on oxidation, mitosis, angiogenesis, as well as its ability to modify the defensive system and adipose tissue metabolism. Moreover, it may have a role in regulation of initiation, promotion, and advancement of cancer. Numerous animal and in-vitro studies suggested that the decrease in serum melatonin discovered in night workers may be the cause of tumor development (Lo Sardo et al. 2017).

As for the effect of melatonin on endometrial thickness, the results of previous studies were conflicting. One of them documented that melatonin administration antagonized nicotine-induced endometrial atrophy and elevated the count of endometrial glands and mucosal folds of the uterine tubes via increasing serum estradiol level and the count of ER- $\alpha$ (Nazanin et al. 2014). On the contrary, another study documented that melatonin administration antagonized estrogen induced endometrial hyperplasia through its anti-estrogen action (Ciortea et al. 2010, 2011). Moreover, Chuffa et al. (2011c) documented that melatonin could decrease plasma estradiol level. Thus, the current study was designed to evaluate the effect of melatonin on endometrial changes induced by estradiol benzoate in female albino rats. We focus in this study on the changes in uterine weight, morphology and microscopic appearance and modifications in the oxidative stress markers, pro-apoptotic markers and markers of inflammation in uterine tissues.

\section{Materials and Methods}

\section{Ethical consent}

According to the instructions of the use and taking care of experimental animals, the action plan was done and approved by the Institutional Ethical Committee, Faculty of Medicine, Minia University, Egypt which is in agreement with the NIH Guide for taking care and use of laboratory animals (National Institutes of Health 1992).

\section{Animals}

At the start of the experiment, thirty six female albino Wister rats were used of age ranging from 4-6 weeks and body weight ranging from 100-150 g. For one week before the beginning of the experiment, rats lived at standard temperature and light/dark cycle and had ad libitum arrival to standard rat chow diet and tap water in the laboratory.

\section{Experimental groups}

Rats were categorized into 3 groups (9 rats per group):

Control group involves 2 subgroups: one subgroup received intramuscular injections of olive oil as a vehicle (Control 1); the other subgroup received drinking water containing ethanol as a vehicle (Control 2).

EB group: rats received three intramuscular injections of estradiol benzoate per week at a dose level of $600 \mu \mathrm{g} / \mathrm{kg}$ for 4 weeks (Refaie and El-Hussieny 2017).

$\mathrm{EB}+\mathrm{Mel}$ group: rats received estradiol benzoate plus melatonin which was put into drinking water at a dose level of $50 \mu \mathrm{g} / \mathrm{ml}$ (Ciortea et al. 2011) for 4 weeks (Khaksar et al. 2017).

\section{Treatment protocol}

Estradiol benzoate (ampoule containing $5 \mathrm{mg}$, Egypt) was dissolved in olive oil (Refaie and El-Hussieny 2017), melatonin (Sigma, USA) was dissolved in 100\% ethanol (ethanol concentration in water $=0.01 \%$ ). Melatonin solution was prepared three times per week, stored in bottles at $-30^{\circ} \mathrm{C}$ and protected from light due its photosensitivity (the bottles were covered with aluminum foil). However, in control group, $100 \%$ ethanol was added to drinking water to reach to a concentration of $0.01 \%$ without adding melatonin (Ciortea et al. 2011). The volume of the consumed melatonin solution was measured by subtracting the weights of the bottles which were measured at the beginning and at the end of 24 hours (Wolden-Hanson et al. 2000). The daily consumption of melatonin solution in melatonin-treated group was estimated to be $60-80 \mathrm{ml}$ containing 3-4 mg melatonin. It was noticed that the volume of solution consumed in melatonin treated group is similar to the volume consumed by the control group. This means that the addition of melatonin to drinking water didn't affect the preference in comparison with the solution which was devoid of melatonin.

\section{Specimen collection}

After one month of treatment, vaginal smears were taken from all rats in the next day at early morning to be checked to determine the estrous stage and then anesthetized by light ether anesthesia and euthanized by beheading. All rats were beheaded at the diestrus stage except the estradiol-treated rats were headed at the estrus stage and this may be due to prolonged estrus stage as a result of exogenous estrogen administration. The pelvis of each rat was opened to remove the uterus. Each uterus was weighed after removal of fat and examined to describe its morphology. Then all uteri were 
divided, some parts were fixed in $10 \%$ buffered formalin for histopathology and immunohistochemistry and the other parts were weighed and kept at $-80^{\circ} \mathrm{C}$ for real time reverse transcription polymerase chain reaction (RT-PCR) and chemical analysis.

\section{Chemical analysis of uterine tissues}

Uterine tissues were homogenized separately in $0.01 \mathrm{M}$ ice cold phosphate buffer with $\mathrm{pH}$ adjusted at 7.4. At $4^{\circ} \mathrm{C}$, in cooling centrifuge, the homogenate was centrifuged at $5000 \mathrm{rpm}$ for $10 \mathrm{~min}$ then the supernatant was gathered for measurement of lipid peroxides and total antioxidant levels according to the method of Ragy et al. (2016) by using colorimetric kits (Biodiagnostic, Egypt).

\section{Uterine histopathology}

Multiple uterine biopsies were taken from the middle third of the horn then fixed, embedded in paraffin and divided. Parts of $7 \mu \mathrm{m}$ in thickness were stained with haematoxylin and eosin (H\&E) stain and examined under light microscope by a pathologist with blind information of pathological data.

\section{Immunohistochemistry assessment of caspase-3}

On positively charged slides (CITOGLAS), 5 micrometer sections were put. With xylene, sections were de-paraffinized and with descending grades of ethanol $(99.9,95$, and 70\%) they were hydrated then treated for half an hour with hydrogen peroxide (3\%) to inactivate endogenous peroxides and swilled in phosphate buffered saline (PBS) solution. By using microwave, sections were treated for $20 \mathrm{~min}$ in citrate buffer with $\mathrm{pH}$ adjusted at 6.0 for antigen retrieval then cooling was allowed. After swilling in PBS, primary antibodies were incubated in a humidity chamber overnight using anti-caspase-3 polyclonal rabbit antibody (Lab Vision Laboratories), then swilled with PBS for 30 min followed by biotinylated secondary antibody (Lab Vision Laboratories) application. In PBS, sections were swilled and incubated for $30 \mathrm{~min}$ with the streptavidin-biotin complex reagent (Lab Vision Laboratories) followed by $5 \mathrm{~min}$ incubation with 3,3 diaminobenzidine tetrahydrochloride which was brought from Lab Vision Laboratories. In distilled water, slides were swilled then counterstained with Mayer's haematoxylin followed by dehydration, clearance in xylene, mounting, and covered slipped. Each staining run had both positive and negative control sections. Primary antibody was left out and substituted by PBS in negative control. For assessment of staining score, sections were visualized under light microscope magnification $\times 200$ or $\times 400$ for positive cells. Cells with cytoplasmic staining are thought to be positive if more than $10 \%$ of the cells were positive (Refaie and El-Hussieny 2017).

\section{RT-PCR of IL-2 and NF- $\kappa B$}

According to the instructions of the producer, ribozol RNA extraction reagent (Amresco, Solon, USA) was used to extract total RNA from homogenized uterine tissue. RT-PCR was done by using Thermo Scientific one step kits in $25 \mu \mathrm{l}$ reaction volume containing $50 \mathrm{ng}$ RNA template and $70 \mathrm{nM}$ of specific primers per reaction in RT-PCR detection system. As compared to the reference gene, the GAPDH (glyceraldehyde-3-phosphate dehydrogenase), the quantity of SYBR green data were assessed. Primers used: IL-2, sense: 5'-CATGTACAGCATGCAGCTCGCATCC-3' and antisense, 5'-CCACCACAGTTGCTGGCTCATCATC-3'. NF- $\kappa$ B, sense, 5' - ACAACCCCTTCCAAGTTCCCT-3', and antisense, 5'- TGGTCCCGTGAAATACACCT-3. The Primer sequence for amplification of GAPDH sense: 5'- GTCGGTGTGAACGGATTTG-3' and antisense 5'- CTTGCCGTGGGTAGAGTCAT-3'. Then the specimens were put in a thermal cycler (Applied Biosyst 7500 fast, Techne (Cambridge) LTD, UK). As described by VanGuilder et al. (2008), the formula $2^{(-\Delta \Delta \mathrm{Ct})}$ was used to estimate the quantitative expression of every gene. The results for each group were presented in graphs as a relative expression in comparison with the control (control value $=1$ ).

\section{Statistical methods}

All individual data in each group were evaluated by graph pad prism software (one way ANOVA test) and the mean \pm standard error of the mean (SEM) for each group was shown in table or figure. These values looked statistically significant if the probability value ( $p$ value) is less than or equals 0.05 .

\section{Results}

\section{Uterine weight and uterine oxidative state}

As shown in Table 1, uterine weight and uterine lipid peroxide level were significantly higher in EB group in comparison with the control group. But melatonin administration with estradiol benzoate significantly decreased both uterine weight and lipid peroxide level as compared to the EB group, but they were still significantly higher in comparison with the control rats.

As for the total antioxidant level, it was significantly decreased in uterine tissue in EB group in comparison with the control group. But melatonin administration with estradiol benzoate caused a significant rise in its level as compared to EB group, but it was still significantly lower in comparison with the control rats (Table 1). 
Table 1. Effect of estradiol benzoate with and without melatonin on uterine weight and uterine oxidative state

\begin{tabular}{lccc}
\hline \multirow{2}{*}{ Parameters } & \multicolumn{3}{c}{ Groups } \\
\cline { 2 - 4 } & Control & EB & EB+Mel \\
\hline Uterine weight $(\mathrm{g})$ & $0.32 \pm 0.03$ & $3.76 \pm 0.07^{\mathrm{O}}$ & $0.58 \pm 0.01^{\mathrm{O}, \bullet}$ \\
Lipid peroxides $(\mathrm{nmol} / \mathrm{mg}$ tissue $)$ & $1.4 \pm 0.09$ & $5.68 \pm 0.2^{\mathrm{O}}$ & $2.63 \pm 0.1^{\mathrm{O}, \bullet}$ \\
Total antioxidant $(\mu \mathrm{m} / \mathrm{mg}$ tissue $)$ & $7.08 \pm 0.1$ & $3.75 \pm 0.08^{\mathrm{o}}$ & $5.76 \pm 0.1^{\mathrm{O}, \bullet}$ \\
\hline
\end{tabular}

Values are expressed as mean \pm SEM of 9 rats in each group. EB, estradiol benzoate; Mel, melatonin. ${ }^{\circ} p<0.05$ versus control group, ${ }^{\bullet} p<0.05$ versus estradiol benzoate-treated group.

\section{Gross features of rat's uterus}

All uteri of different groups were examined for abnormal gross features. The control uteri didn't show any abnormalities. However, in EB group, the uterine horns showed marked dilatation and contained thick and turbid fluid. In $\mathrm{EB}+\mathrm{Mel}$ group, the uterine horns showed mild dilatation and contained thin and clear fluid.

\section{Uterine sections $H$ and $E$ stain}

Histological examination of uterine sections in control rats revealed normal appearance of proliferative endometrium, normal gland shape lined by cuboidal cells with nuclei small and round in shape, normal ratio between glands and stroma, the stroma was abundant with less inflammatory cells infiltration and no luminal dilation (Fig.
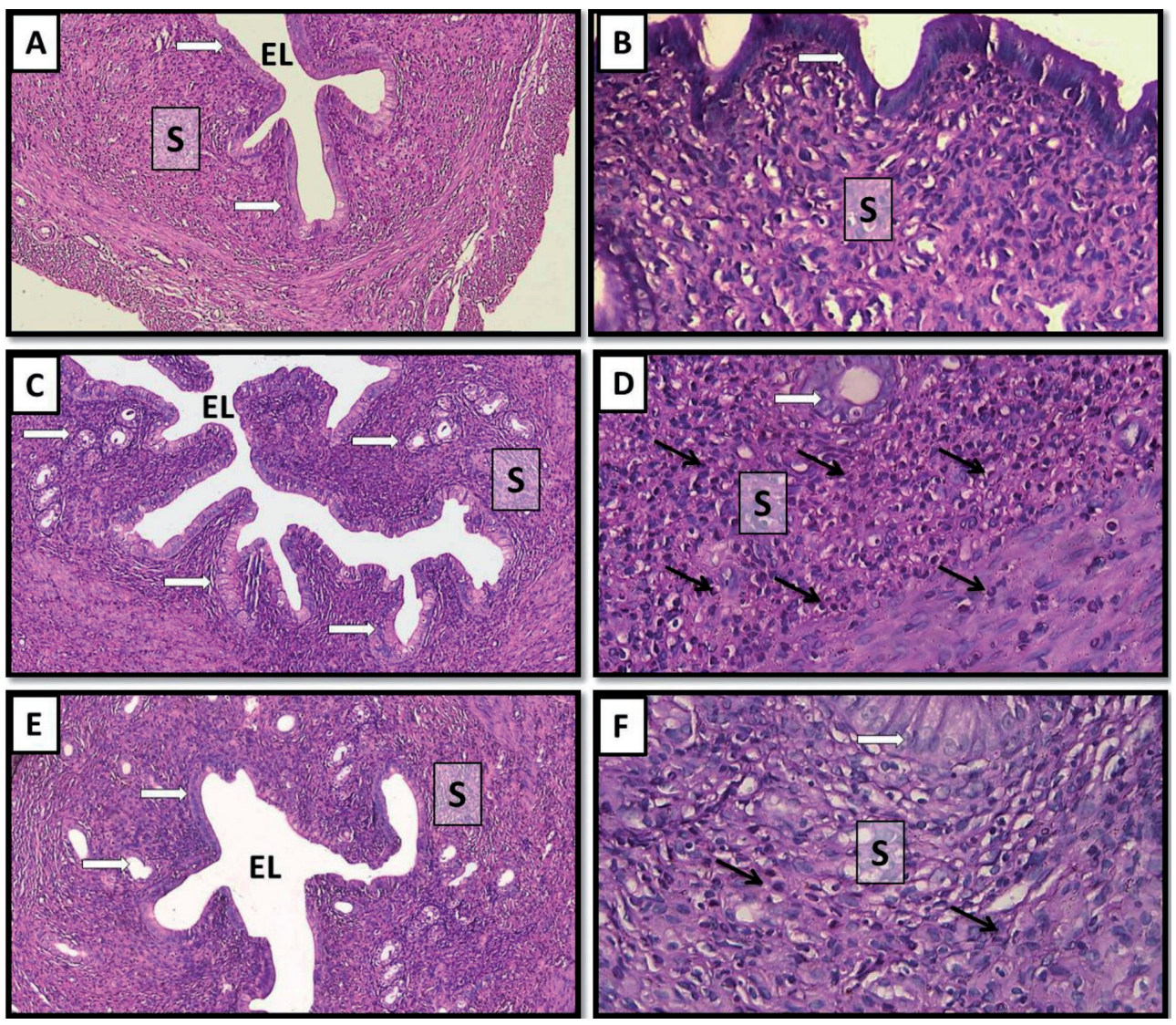

Figure 1. Histopathological examination of uterine sections. Control groups: normal proliferative endometrium with normal gland (white arrows) to stroma ratio and narrow endometrial lumen (A, 100×); higher magnification of the stroma showed no inflammatory infiltration and no atypia of the glandular mucosa (white arrows) (B, 400×). EB group (estradiol benzoatetreated rats): majority of the examined sections showed severe endometrial hyperplasia with atypia (white arrows), increased gland to stroma ratio, stroma was markedly infiltrated with inflammatory cells (black arrows) and endometrial lumen was markedly dilated (C, 100x); higher magnification of the stroma that showed marked inflammatory infiltration (black arrows) and severe atypia (white arrows) of the glandular mucosa $(D$, $400 \times$ ). EB+Mel group (estradiol benzoate + melatonintreated rats): showed simple endometrial hyperplasia freed from atypia (white arrows) and mild luminal dilatation was present $(\mathbf{E}, 100 \times)$; higher magnification of the stroma showed mild inflammatory infiltration (black arrows) and no atypia of the endometrial glands (white arrows) (F, 400×). EL, endometrial lumen; S, stroma; black arrows, stromal inflammatory cells; white arrows, endometrial epithelial cells. 
1A,B). In EB group, there was endometrial hyperplasia with irregular gland shape and showing stratification, the ratio between glands to stroma increased, marked infiltration of stroma with inflammatory cells, marked luminal dilatation and focal atypia was detected in the epithelium characterized by loss of polarity associated with disparate shape of nuclei with notable nucleoli (Figure 1C,D). In $\mathrm{EB}+\mathrm{Mel}$ group, there was a picture of simple endometrial hyperplasia free from atypia, mild luminal dilation and the stroma appeared with less inflammatory cells permeation (Figure 1E,F).

\section{Immunohistochemistry assessment of caspase-3}

As shown in Figure 2, uterine sections were examined for caspase- 3 antibody expression. In control and EB groups, caspase-3 expression was negative. But in $\mathrm{EB}+\mathrm{Mel}$ group, caspase- 3 expression was positive.

\section{Relative expression of NF- $\kappa B$ and IL-2 by RT-PCR}

The results proved that administration of estradiol benzoate caused a significant rise in NF- $\kappa \mathrm{B}$ mRNA level in comparison with the control rats. When melatonin was administrated with estradiol benzoate, a significant decrease in NF- $\kappa B$ mRNA level was observed but its level was still significantly higher relative to the control rats (Figure 3A).

Relative to the control rats, in EB rats, IL-2 mRNA level was significantly decreased. A significant increase in IL-2 mRNA level was found in $\mathrm{EB}+\mathrm{Mel}$ group, however, its level was still lower than the control rats (Figure 3B).

\section{Discussion}

Endometrial proliferation may occur due to shift towards the direction of estrogen or a loss of its antagonist, the progesterone (Kubyshkin et al. 2016). Endometrial hyperplasia was induced in the present study by exogenous estradiol benzoate administration confirmed by histopathological picture as found by Refaie and El-Hussieny (2017). Asaka et al. (2017) reported that the higher estradiol blood level may act directly on endometrial epithelial cells and enhance its mitotic division. Zhang et al. (2017) reported that estradiol binding during the initial stages of endometrial cancer may stimulate estrogen target genes expression which augmented proliferation of cells and caused deoxyribonucleic acid (DNA) errors or mutations.

Exposure to excess estrogen could stimulate encroachment of endometrial tissue with inflammatory cells which enhances the production of pro-inflammatory cytokines (Veiga et al. 2017). Pro-inflammatory cytokines could stimulate the production of estrogen within the endometrium via enhancing the expression of aromatase enzyme in stromal cells which converts androgen to estrogen. Endometrial estrogen may act in a paracrine or autocrine fashion and make the condition worse. Thus, higher estradiol blood level plays a role in the beginning of endometrial hyperplasia development, but other mechanisms may be involved in the transformation of simple endometrial hyperplasia to the complex type with or without atypia. Plenty mechanisms are involved in the development of tumor with chronic inflammation. One of them is the tissue injury caused by more production of reactive oxygen (ROS) and nitrogen species by leukocytes. Recurrent damage and regeneration of tissues may result in
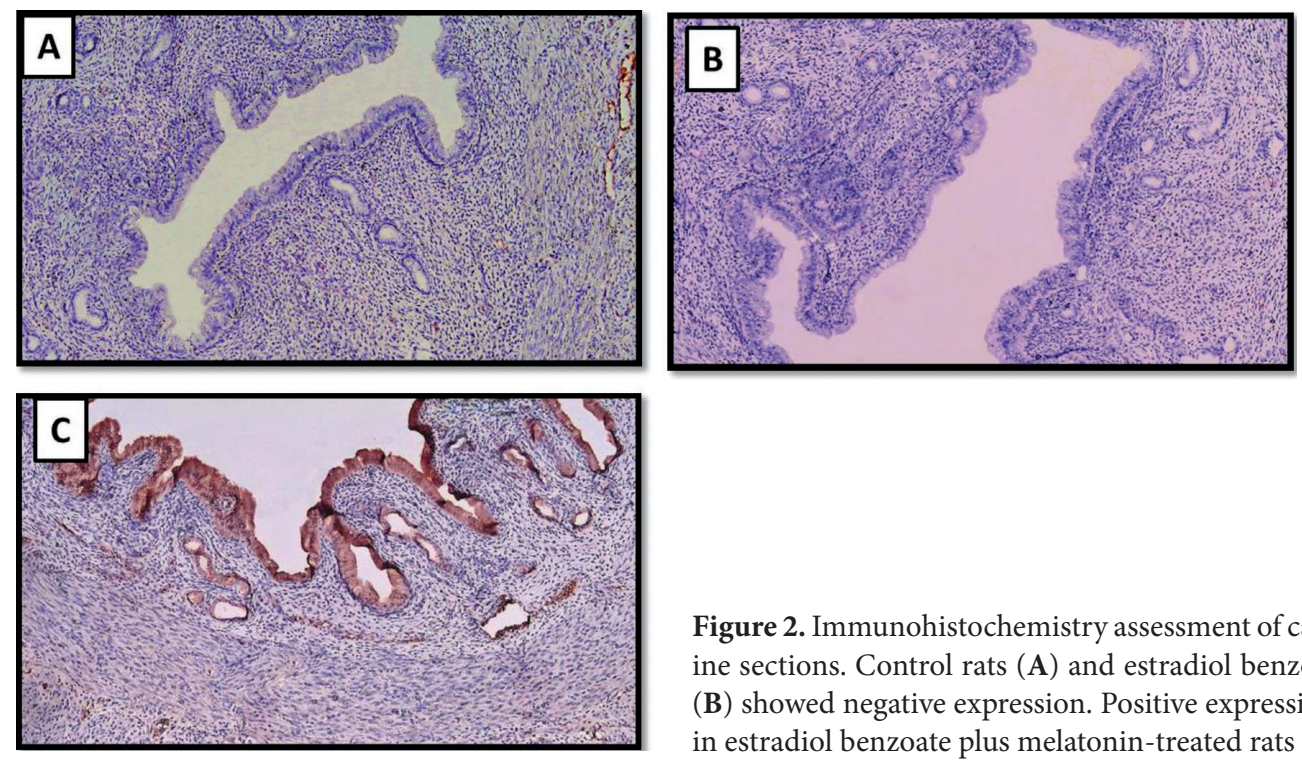

Figure 2. Immunohistochemistry assessment of caspase-3 in uterine sections. Control rats (A) and estradiol benzoate-treated rats (B) showed negative expression. Positive expression was detected in estradiol benzoate plus melatonin-treated rats (C). 
A

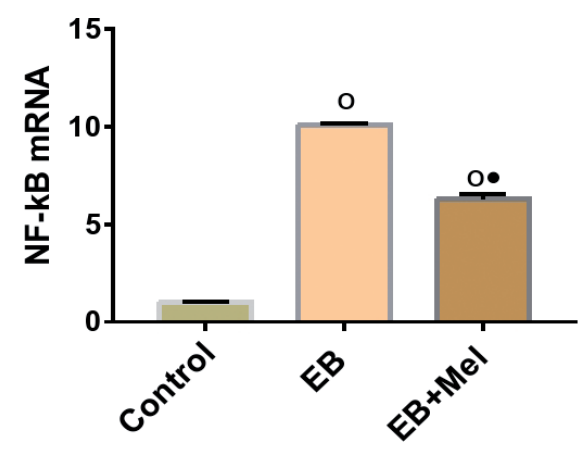

B

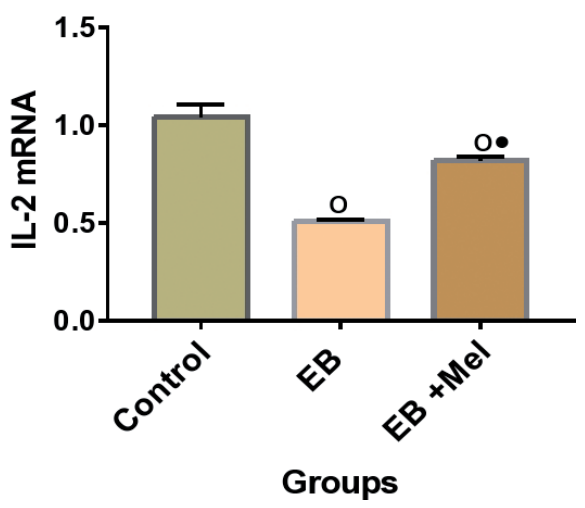

Figure 3. Effect of estradiol benzoate (EB) with and without melatonin (Mel) on expression of NF- $\mathrm{kB}$ gene (A) and IL-2 gene (B). Values of 9 rats in each group are presented in the form of mean \pm SEM. NF- $\kappa B$, nuclear factor kappa-light-chain-enhancer of activated B cell; IL-2, interleukine- $2 .{ }^{\circ} p<0.05$ versus control group, $\bullet p<0.05$ versus estradiol benzoate-treated group.

persistent genomic deterioration. This is compatible with endometrial atypical changes in histopathological picture with estradiol benzoate (Kubyshkin et al. 2016).

A typical endometrial hyperplasia detected with estradiol benzoate in the present study is a precancerous condition. The present study was conducted on rats at young age which represents the age of development, cell division, growth and expression of receptors and this made these rats too sensitive to the carcinogenic potential of endocrine disturbing chemicals and drugs. Thus, young rats were ideal for performing this study and ovariectomy was not performed on these rats. This means that the increased availability of estrogen to the estrogen sensitive endometrium increases the risk of endometrial cancer even in young age (Yang et al. 2015).

Endometrial hyperplasia may occur due local imbalance between pro-inflammatory and anti-inflammatory cytokines (Lysenko 2013). In the current study, the increased expression of NF- $\kappa \mathrm{B}$ in uterine tissues with estradiol may be a possible mechanism of endometrial inflammation as found by Shukla et al. (2015); Koc et al. (2017). Pro-inflammatory cytokines and/or ROS activate the transcription of NF-kB leading to increased production and expression of inflammatory mediators and so on making a vicious cycle (Favero et al. 2017). The increased NF- $\mathrm{kB}$ gene expression might be responsible for the anti-apoptotic action of estradiol on rat's uterus because it has the ability to activate the expression of anti-apoptotic genes. This is in agreement with the decreased immune-expression of caspase- 3 with estradiol as found by Refaie and El-Hussieny (2017). On the other hand, certain study reported that estradiol suppressed the expression of anti-inflammatory cytokines such as IL-2 as evident in the present study. And this agrees with Joung et al. (2015); Refaie and El-Hussieny (2017) who mentioned that inhibition of inflammatory signaling could reduce cancer incidence

In the present study, in uterine tissues, lipid peroxides was significantly increased and total antioxidant level was significantly decreased with estradiol benzoate treatment as found by Pejić et al. (2015); Refaie and El-Hussieny (2017). Intense ROS production by inflammatory cells could initiate lipid peroxidation (Razavi et al. 2017). Moreover, Yuan et al. (2014) mentioned that unopposed estrogen modified the expression of genes involved in oxidative stress in rat's uterus that may result in endometrial cancer. This was confirmed by Refaie and El-Hussieny (2017) who documented that in comparison with healthy individuals or individuals with benign lesions, tissue lipid peroxidation was augmented in individuals with endometrial hyperplasia and cancer. On the other hand, long exposure to oxidative stress could elevate free radical production and induce utilization of antioxidants and this increases the incidence of endometrial cancer (Refaie and El-Hussieny 2017). In addition, Bellanti et al. (2013) documented that estradiol exposure represses the expression of antioxidants via inhibition of the antioxidant response element-mediated gene transcription. Due to all previous effects of estradiol including overgrowth, inhibition of apoptosis, and inflammation of the endometrium, the uterine weight was significantly higher as detected by Shang et al. (2017) which was reduced by melatonin administration (Şahin et al. 2015).

Histopathological examination of rats' uteri treated with melatonin revealed that melatonin reduced estradiol induced endometrial hyperplasia and prevented the occurrence of atypia. This agrees with Ciortea et al. (2011) who mentioned that the anti-proliferative action of melatonin may be due to its antagonistic action on estrogen which was achieved by multiple mechanisms; melatonin involved in the metabolism of estrogen transforms estradiol into inactive estrogen sulfate (González-González et al. 2018). In addition, melatonin suppresses estrogen receptors expression and disrupts its cell signaling (Kubatka et al. 2018).

Melatonin significantly reduced lipid peroxidation induced by estradiol associated with a significant increase in 
total antioxidant level in uterine tissues. Several studies have confirmed that melatonin has an antioxidant action. First, melatonin can stimulate the activities and expression of antioxidant enzymes that contribute to the protection against the damage caused by oxidative stress (Chuffa et al. 2011b). Second, it detoxifies a variety of free radicals and reactive oxygen molecules including hydroxyl radical, superoxide, peroxynitrites and singlet oxygen (Kocic et al. 2017). Third, it acts as a free radical scavenger of oxidative products and prevents lipid peroxidation in reproductive tissues (Chuffa et al. 2011a).

Melatonin exerted an anti-inflammatory effect through its suppressor action on oxidative stress induced NF- $\kappa$ B expression as found in the present study and by other investigators (Nayki et al. 2016; Favero et al. 2017). Moreover, a previous study documented that melatonin not only reduced NF- $\kappa B$ expression but also reduced its nuclear translocation and DNA binding activity (Mohammadi et al. 2016). On the other hand, the prophylactic effect of melatonin on estradiol benzoate-induced endometrial hyperplasia is possibly caused by enhancing the expression of anti-inflammatory cytokines as found in our study by increasing IL-2 mRNA level in uterine tissue. This is compatible with Cardinali et al. (2016) who documented that melatonin bind with its receptors on T-helper cells to increase IL-2 production which increases the number and activity of natural killer cells. This proved that melatonin may exert an anticancer effect via its immunomodulator action.

Li et al. (2017) reported that the inhibitory action of melatonin on NF- $\mathrm{BB}$ expression may be also the cause of its pro-apoptotic action as evident in the present study. Melatonin induced apoptosis maybe through p53 pathway activation which enhances the transcriptional activation of the pro-apoptotic, cell cycle arrest, and DNA repair. Its proapoptotic action may also include the mitochondrial pathway via enhancing the release of mitochondrial pro-apoptotic agents. The mechanisms of the preceding effect may include mitochondrial membrane depolarization and permeability transition pore induction (Cardinali et al. 2016).

Concerning the effect of melatonin on uterine tissues, there are controversial results. A previous study in rats showed that melatonin administration reduced caspase- 3 activity and induced bcl 2 expression via mitochondrial pathways (Tamura et al. 2009). Nazanin et al. (2014) showed that melatonin administration antagonized nicotine action on rat's uterus and increased endometrial thickness by increasing serum estradiol level and the number of ER- $\alpha$. The different melatonin doses, duration of treatment, experimental protocol, and rats' strains among the studies may be the causes of contradictory results.

In conclusion, the current study proved that melatonin reduced endometrial hyperplasia and prevented the occurrence of atypia induced by estradiol via its antagonistic ac- tions on inflammation and oxidation and its agonistic action on apoptosis. These actions are based on our results which include its inhibitory effect on NF- $\kappa$ B gene expression and lipid peroxidation in uterine tissues. Also, it significantly increased immunoexpression of caspase-3, gene expression of IL-2 and total antioxidant level in uterine tissues.

\section{References}

Asaka R, Miyamoto T, Yamada Y, Ando H, Mvunta DH, Kobara H, Kashima H, Shiozawa T (2017): Elevated serum levels of estradiol induce endometrial hyperplasia rather than carcinoma in a mouse model using a carcinogen. J. Carcinog. Mutagen 8, 308 https://doi.org/10.4172/2157-2518.1000308

Bellanti F, Matteo M, Rollo T, De Rosario F, Greco P, Vendemiale G, Serviddio G (2013): Sex hormones modulate circulating antioxidant enzymes: impact of estrogen therapy. Redox Biol. 1, 340-346 https://doi.org/10.1016/j.redox.2013.05.003

Cardinali D, Escames G, Acu-a-Castroviejo D, Ortiz F, FernándezGi BA, García-López S, Shen Y, Florido J (2016): Melatonininduced oncostasis, mechanisms and clinical relevance. J. Integr. Oncol. 2016, S1

https://doi.org/10.4172/2329-6771.S1-006

Chuffa LGA, Amorim JP, Teixeira GR, Mendes LO, Fioruci BA, Pinheiro PF, Almeida-Francia CC (2011a): Long-term exogenous melatonin treatment modulates overall feed efficiency and protects ovarian tissue against injuries caused by ethanolinduced oxidative stress in adult UChB rats. Alcohol Clin. Exp. Res. 35, 1498-1508 https://doi.org/10.1111/j.1530-0277.2011.01486.x

Chuffa LGA, Amorim JPA, Teixeira GR, Mendes LO, Fioruci BA, Pinheiro PFF, Martinez FE (2011b). Long-term melatonin treatment reduces ovarian mass and enhances tissue antioxidant defenses during ovulation in the rat. Braz. J. Med. Biol. Res. 44, 217-223 https://doi.org/10.1590/S0100-879X2011007500018

Chuffa LG, Seiva FR, Fávaro WJ, Teixeira GR, Amorim JP, Mendes LO, Fioruci BA, Pinheiro PF, Fernandes AA, Franci JA, Delella FK, Martinez M, Martinez FE (2011c): Melatonin reduces LH, 17 beta-estradiol and induces differential regulation of sex steroid receptors in reproductive tissues during rat ovulation. Reprod. Biol. Endocrinol. 9, 108 https://doi.org/10.1186/1477-7827-9-108

Chuffa LGA, Seiva FR, Fávaro WJ, Amorim JPA, Teixeira GR, Mendes LO, Martinez FE (2013): Melatonin and ethanol intake exert opposite effects on circulating estradiol and progesterone and differentially regulate sex steroid receptors in the ovaries, oviducts, and uteri of adult rats. Reprod. Toxicol. 39, 40-49 https://doi.org/10.1016/j.reprotox.2013.04.001

Ciortea R, Costin N, Groza D, Mocan R, Şuşman S, Bondor C, Mihu C, Mihu D (2010): Effect of melatonin on endometrial proliferation in ovariectomized female rats. Gineco. 6, 47-55 Ciortea R, Costin N, Braicu I, Haragâş D, Hudacsko A, Bondor C, Mihu D, Mihu CM (2011): Effect of melatonin on intra- 
abdominal fat in correlation with endometrial proliferation in ovariectomized rats. Anticancer Res. 31, 2637-2643

Clement NS, Oliver TR, Shiwani H, Sanner JR, Mulvaney CA, Atiomo W (2017): Metformin for endometrial hyperplasia. Cochrane Database Syst. Rev. 10, CD012214 https://doi.org/10.1002/14651858.CD012214.pub2

Favero G, Franceschetti L, Bonomini F, Rodella L, Rezzani R (2017): Melatonin as an anti-inflammatory agent modulating inflammasome activation. Int. J. Endocrinol. 2017, 1-13 https://doi.org/10.1155/2017/1835195

González-González A, Mediavilla MD, Sánchez-Barceló EJ (2018): Melatonin: a molecule for reducing breast cancer risk. Molecules $\mathbf{2 3}, 336$ https://doi.org/10.3390/molecules23020336

Joung KH, Jeong JW, Ku BJ (2015): The association between type 2 diabetes mellitus and women cancer: the epidemiological evidences and putative mechanisms. Biomed. Res. Int. 2015, 1-12 https://doi.org/10.1155/2015/920618

Kaushal J, Sankhwar P, Kumari S, Popli P, Shukla V, Hussain M, Hajela K, Dwivedi A (2017): The regulation of Hh/Gli1 signaling cascade involves Gsk $3 \beta$ - mediated mechanism in estrogenderived endometrial hyperplasia. Sci. Rep. 7, 6557 https://doi.org/10.1038/s41598-017-06370-1

Khaksar M, Oryan A, Sayyari M, Rezabakhsh A, Rahbarghazi R (2017): Protective effects of melatonin on long-term administration of fluoxetine in rats. Exp. Toxicol. Pathol. 69, 564-574 https://doi.org/10.1016/j.etp.2017.05.002

Koc O, Ozdemirici S, Acet M, Soyturk U, Aydin S (2017): Nuclear factor- $\kappa \mathrm{B}$ expression in the endometrium of normal and overweight women with polycystic ovary syndrome. J. Obstet. Gynaecol. 37, 924-930 https://doi.org/10.1080/01443615.2017.1315563

Kocic G, Tomovic K, Kocic H, Sokolovic D, Djordjevic B, Stojanovic S, Arsic I, Smelcerovic A (2017): Antioxidative, membrane protective and antiapoptotic effects of melatonin, in silico study of physico-chemical profile and efficiency of nanoliposome delivery compared to betaine. RSC Adv. 7, 1271-1281 https://doi.org/10.1039/C6RA24741E

Kubatka P, Zubor P, Busselberg D, Kwon TK, Adamek M, Petrovic D, Opatrilova R, Gazdikova K, Caprnda M, Rodrigo L, Danko J, Kruzliak P (2018): Melatonin and breast cancer: Evidences from preclinical and human studies. Crit. Rev. Oncol. Hematol. 122, 133-143 https://doi.org/10.1016/j.critrevonc.2017.12.018

Kubyshkin AV, Aliev LL, Fomochkina II, Kovalenko YP, Litvinova SV, Filonenko TG, Lomakin NV, Kubyshkin VA, Karapetian OV (2016): Endometrial hyperplasia-related inflammation: its role in the development and progression of endometrial hyperplasia. Inflamm. Res. 65, 785-794 https://doi.org/10.1007/s00011-016-0960-z

Li W, Wang Z, Chen Y, Wang K, Lu T, Ying F, Fan M, Li , Wu J. (2017): Melatonin treatment induces apoptosis through regulating the nuclear factor- $\mathrm{\kappa B}$ and mitogen-activated protein kinase signaling pathways in human gastric cancer SGC7901 cells. Oncol. Lett. 13, 2737-2744 https://doi.org/10.3892/ol.2017.5785

Lo Sardo F, Muti P, Blandino G, Strano S (2017): Melatonin and hippo pathway: is there existing cross-talk? Int. J. Mol. Sci. 18, E1913 https://doi.org/10.3390/ijms18091913

Lysenko OV (2013): Benign endometrial lesions in premenopausal women: three-dimensional power Doppler sonography and cytokines content. Prog. Health Sci. 3, 1-6

Mohammadi M, Rezaie MJ, Rostamzadeh A, Allahveisi A, Mohammadi HR, Mohammadi F, Moayeri A (2016): Signaling pathways of melatonin in prevention of liver disorders via suppressing of oxidative stress in cellular level. Biomed. Pharmacol. J. 9, 555-561 https://doi.org/10.13005/bpj/972

National Institutes of Health (1992): Institutional Animal Care and Use Committee Guidebook. NIH Publication no. 92-3415. Washington, D.C.: U.S. Government Printing Office

Nayki U, Onk D, Balci G, Nayki C, Onk A, Çankaya M, Taskın Kafa AH, Kuzucu M (2016): The effect of melatonin on oxidative stress and apoptosis in experimental diabetes mellitus-related ovarian injury. Gynecol. Endocrinol. 32, 421-426 https://doi.org/10.3109/09513590.2015.1126819

Nazanin S, Saadat SN, Mohammadghasemi F, Jahromi SK, Homafar MA, Haghiri M (2014): Melatonin protects uterus and oviduct exposed to nicotine in mice. Interdiscip. Toxicol. 7, 41-46 https://doi.org/10.2478/intox-2014-0007

Pejić S, Stojiljković V, Todorović A, Gavrilović L, Popović N, Pavlović I, Pajović SB (2015): Antioxidant status in blood of gynaecological patients: influence of diagnosis and reproductive factors. Folia Biol. (Praha) 61, 26-32

Ragy M, Ali F, Ramzy M (2016): Effect of hemin on brain alterations and neuroglobin expression in water immersion restraint stressed rats. Scientifica J. 2016, 1-8 https://doi.org/10.1155/2016/7825396

Razavi S, Seghinsara A, Abedelahi A, Salimnejad R, Tayefi H (2017): Effect of vitamin $\mathrm{E}$ and selenium on oxidative stress and tissue damages induced by electromagnetic fields in immature mice ovarian. CJMB 4, 120-125

Refaie M, El-Hussieny M (2017): The role of interleukin-1b and its antagonist (diacerein) in estradiol benzoate-induced endometrial hyperplasia and atypia in female rats. Fundam. Clin. Pharmacol. 31, 438-446 https://doi.org/10.1111/fcp.12285

Şahin L, Şahin H, Karahan F, Gül S, Bahar L, Gül M, Özakşit M (2015): Can melatonin protect the endometrium from the adverse effects of caerulein? Kafkas Univ. Vet Fak. Derg. 21, 673-676

Shang CG, Liu ZH, Wang XH, Feng ZH, Zhang Y (2017): Effect of high-fat diet-induced disorders on rat with endometrial hyperplasia and adiponectin system in circulation and uterus. Chin. Med. J. (Engl). 130, 1831-1837 https://doi.org/10.4103/0366-6999.211551

Shukla V, Chandra V, Sankhwar P, Popli P, Kaushal J, Sirohi V, Dwivedi A (2015): Phytoestrogen genistein inhibits EGFR/ $\mathrm{PI} 3 \mathrm{~K} / \mathrm{NF}-\mathrm{kB}$ activation and induces apoptosis in human endometrial hyperplasial cells. RSC Adv. 5, 56075-56085 https://doi.org/10.1039/C5RA06167A

Sobczuk K, Sobczuk A (2017): New classification system of endometrial hyperplasia WHO 2014 and its clinical implications. Menopause Rev. 16, 107-111 https://doi.org/10.5114/pm.2017.70589

Tamura H, Nakamura Y, Korkmaz A, Manchester LC, Tan DX, Sugino N, Reiter RJ (2009): Melatonin and the ovary: physi- 
ological and pathophysiological implications. Fertil. Steril. 92, 328-343

https://doi.org/10.1016/j.fertnstert.2008.05.016

Tordjman S, Chokron S, Delorme R, Charrier A, Bellissant E, Jaafari N, Fougerou C (2017): Melatonin: pharmacology, functions and therapeutic benefits. Curr. Neuropharmacol. 15, 434-443

https://doi.org/10.2174/1570159X14666161228122115

VanGuilder HD, Vrana KE, Freeman WM (2008): Twenty-five years of quantitative PCR for gene expression analysis. Biotech. 44, 619-626 https://doi.org/10.2144/000112776

Veiga GA, Miziara RH, Angrimani DS, Papa PC, Cogliati B, Vannucchi C (2017): Cystic endometrial hyperplasia-pyometra syndrome in bitches: identification of hemodynamic, inflammatory, and cell proliferation changes. Biol. Reprod. 96, 58-69

Wolden-Hanson T, Mitton DR, McCants RL, Yellon SM, Wilkinson CW, Matsumoto AM, Rasmussen DD (2000): Daily melatonin administration to middle-aged male rats suppresses body weight, intraabdominal adiposity, and plasma leptin and insulin independent of food intake and total body fat. Endocrinol. 141, 487-497 https://doi.org/10.1210/endo.141.2.7311

Yang CH, Almomen A, Wee YS, Jarboe EA, Peterson CM, JanátAmsbury MM (2015): An estrogen-induced endometrial hyperplasia mouse model recapitulating human disease progression and genetic aberrations. Cancer Med. 4, 1039-1050 https://doi.org/10.1002/cam4.445

Yuan L, Dietrich AK, Nardulli AM (2014): 17ß-Estradiol alters oxidative stress response protein expression and oxidative damage in the uterus. Mol. Cell. Endocrinol. 382, 218-226 https://doi.org/10.1016/j.mce.2013.09.023

Zhang J, Xu H, Zhou X, Li Y, Liu T, Yin X, Zhang B (2017): Role of metformin in inhibiting estrogen-induced proliferation and regulating ER- $\alpha$ and ER- $\beta$ expression in human endometrial cancer cells. Oncol. Lett. 14, 4949-4956 https://doi.org/10.3892/ol.2017.6877

Received: May 11, 2018

Final version accepted: August 30, 2018

First published online: January 18, 2019 